\title{
GLUCAN AND RESVERATROL COMPLEX - POSSIBLE SYNERGISTIC EFFECTS ON IMMUNE SYSTEM
}

\author{
Vaclav Vetvicka ${ }^{\mathrm{a}}$, Tomas Volny ${ }^{\mathrm{b}}$, Sujata Saraswat-Ohria ${ }^{\mathrm{a}}$, Aruna Vashishta ${ }^{\mathrm{a}}$, Zuzana Vancikova ${ }^{\mathrm{c}}$, \\ Jana Vetvickova ${ }^{\mathrm{a}}$
}

a University of Louisville, Department of Pathology, Louisville, KY 40202, USA;

${ }^{b}$ Innovation Institute, Opava, Czech Republic,

c Hospital Motol, Prague 5, Czech Republic

e-mail:Vaclav.vetvicka@louisville.edu

Received: March 29, 2007; Accepted (with revision): May 23, 2007

Key words: Glucan/Resveratrol complex/Phagocytosis/Immune reactions/Gene

Background: Recent data showing that glucan elicited defense responses in grapevine and induced protection via induction of resveratrol production led us to evaluate the possible synergetic effects of glucan and resveratrol complex on immune reactions.

Methods: We measured phagocytosis using HEMA particles, expression of cell surface markers via flow cytometry, expression of cytokines using ELISA, recovery after fluouracil-induced leucopenia and effects on gene expression via RT-PCR.

Results: Our results showed that both glucan and resveratrol complex stimulated phagocytosis of blood leukocytes, caused increase in surface expression of $\mathrm{CD}^{+}$splenocytes and showed higher restoration of spleen recovery after experimentally induced leucopenia. In all these cases, strong synergetic effects were observed. When we measured the effects of these substances on expression level of NF-kB2, Cdc42 and Bcl-2 in breast cancer cells, upregulation of Cdc42 expression was evident only using both immunomodulators in combination.

Conlusions: In conclusion, our data suggest significant synergy in stimulation of immune reactions and support further studies of these natural immunomodulators.

\section{INTRODUCTION}

$\beta-1,3-$ Glucan's role as a biologically active immunomodulator has been well documented for over 40 years. Initial interest in the immunomodulatory properties of polysaccharides was raised after experiments showed that a crude yeast cell preparation stimulated macrophages via activation of the complement system ${ }^{1}$. Further work identified the immunomodulatory active component as $\beta-1,3$-glucan ${ }^{2}$. Numerous studies have subsequently shown that $\beta$-1,3-glucans, either particulate or soluble, exhibit immunostimulating properties, including antibacterial and anti-tumor activities ${ }^{3}$. At this time, glucans are considered to be one of the most efficient biological response modifiers.

More than 1,800 publications have reported that $\beta$-1,3-glucans, either soluble or particulate, exhibit significant immunomodulatory properties. However, from this vast amount of data, only limited information about immunostimulation of human immune system is available. Browder et al. ${ }^{4}$ described a strong decrease in septic morbidity. A well-documented multicenter blind study demonstrated that glucan-treated patients had significantly lower infections ${ }^{5}$. The same type of glucan was also shown to reduce infection-stimulated periapical bone resorption ${ }^{6}$. Positive effects were found in patients after cardiopulmo- nary bypass and inhibition of antiviral activity has been found in HIV-infected patients ${ }^{7}$. Some $\beta$-glucans have been routinely used in patients for tumor immunotherapy ${ }^{8}$. In addition to the immunomodulatory effects, $\beta$-glucans were also shown to reduce the cholesterol levels of hypercholesterolemic patients ${ }^{9}$.

A variety of $\beta-1,3$ glucans have been shown to bind to glucan receptors on monocytes, macrophages, neutrophils and NK cells ${ }^{10,11}$. Despite the progress, it is not clear if there is a separate receptor for glucan ${ }^{10}$, only CR3 (CD11b/CD18) receptor ${ }^{11}$, dectin-1 receptor ${ }^{12}$, or a combination of all these receptors. As biological effects of glucans appear to be multifactorial, it is not surprising that glucans also influence the production and secretion of cytokines.

Resveratrol (trans-3,4',5-trihydroxystilbene) is nonflavonoid polyphenol found in various fruits and vegetables and is abundant in grape skin. In addition to various biochemical, biological and pharmacological activities, resveratrol has been found to exhibit numerous immunomodulatory activities such as suppression of lymphocyte proliferation, changes in cell-mediated cytotoxicity, cytokine production ${ }^{13}$ or induction of apopto$\mathrm{sis}^{14}$. In addition, resveratrol has been reported to exhibit a cancer-chemopreventive activity ${ }^{15}$. 
Recent observation showing that seaweed-derived glucan elicited defense responses in grapevine and induced protection against Botrytis cinerea and Plasmopara viticola via induction of production of two phytoalexins including resveratrol ${ }^{16}$ led us to evaluate the possible synergetic effects of glucan and resveratrol complex on immune reactions.

\section{MATERIAL AND METHODS}

\section{Animals}

Female, 6-to-10 week old BALB/c mice were purchased from the Jackson Laboratory (Bar Harbor, ME). All animal work was done according to the University of Louisvile IACUC protocol. Animals were sacrificed by $\mathrm{CO}_{2}$ asphyxiation.

\section{Materials}

RPMI 1640 medium, sodium citrate, antibiotics, sodium azide, bovine serum albumine (BSA), ovalbumin, Wright stain, Freund's adjuvant and Concanavalin A were obtained from Sigma Chemical Co. (St. Louis, MO), fetal calf serum (FCS) was from Hyclone Laboratories (Logan, UT).

\section{Antibodies}

For fluorescence staining, the following antibodies have been employed: anti-mouse CD4, CD8, CD11b and CD19, conjugated with FITC were purchased from Biosource (Camarillo, CA), anti-mouse CD71 and CD122, also conjugated with FITC, were purchased from Pharmingen (San Diego, CA).

\section{Flow cytometry}

Cells were stained with monoclonal antibodies on ice in 12 x 75-mm glass tubes using standard techniques for 30 minutes on ice. After washing with cold PBS, the cells were resuspended in PBS containing 1\% BSA and $10 \mathrm{mM}$ sodium azide. Flow cytometry was performed with a FACScan (Becton Dickinson, San Jose, CA) flow cytometer and the data from over 10,000 cell/sample were analyzed.

\section{$\beta-1,3$ glucan \\ Yeast-derived WGP glucan was purchased from Biothera (Eagan, MN).}

\section{Resveratrol complex}

The mixture of purified powdered extract from roots of Polygonum cuspidatum and fruits of Vitis vinifera (the usual ratio $3: 1$ ) was standardized to $\min .50 \%(\mathrm{w} / \mathrm{w})$ trans-resveratrol and resveratrol glycosides (the usual ratio $1: 4$, HPLC, external standard as trans-resveratrol and piceid). Piceid (trans-resveratrol- $\beta$-D-glukopyranosid) is the major glycoside, resveratroloside and piceatannol glucoside are the minor ones. The preparation also contains emodin complex (emodin and its glycosides, HPLC, external standard as emodin), standardized to $1-4,5 \%$ (w/w).

\section{Phagocytosis}

The technique employing phagocytosis of synthetic polymeric microspheres was described earlier ${ }^{17}$. Briefly: peritoneal cells were incubated with $0.05 \mathrm{ml}$ of 2-hydroxyethyl methacrylate particles (HEMA; $5 \times 10^{8} / \mathrm{ml}$ ). The test tubes were incubated at $37^{\circ} \mathrm{C}$ for 60 min with intermittent shaking. Smears were stained with Wright stain. The cells with three or more HEMA particles were considered positive. The same smears were also used for evaluation of cell types. The same technique was used for evaluation of phagocytosis of peripheral blood cells ${ }^{17}$.

\section{5-Fluorouracil}

Mice were injected i.v. with $0.1 \mathrm{ml}$ of 5-fluorouracil ( $3 \mathrm{mg} / \mathrm{mouse}$ ). From day 0 , mice were injected ip. daily with $100 \mu \mathrm{g}$ of tested substance. At different time intervals, individual mice were sacrificed and the cellularity in bone marrow and spleen was evaluated.

The numbers of cells in bone marrow were evaluated as follows: mice were sacrificed by cervical dislocation, the legs were separated from the body at the hip joint and the feet were removed. The legs were placed in a Petri dish obtaining RPMI 1640 medium. All muscle tissue from the femurs and tibia was removed and the bones were separated (only femurs were used). The epiphyses were cut off on both ends; the bone end was punctured with a $23 \mathrm{G}$ needle and flushed out with $3 \mathrm{ml}$ of warm $\left(22^{\circ} \mathrm{C}\right)$ RPMI 1640 medium. The large debris and cell clumps were removed by layering the cell suspension over $3 \mathrm{ml}$ of heat-inactivated FCS for 10 minutes on ice. The cells collected from the top of FCS were washed once by centrifugation at $300 \times \mathrm{g}$ for 10 minutes at $4{ }^{\circ} \mathrm{C}$ and kept in RMPI 1640 medium containing $5 \%$ FCS. One drop of the final solution was dropped into hemocytometer and counted under an optical microscope. The same technique was used for counting of isolated splenocytes.

\section{Cytokine assay}

$\mathrm{BALB} / \mathrm{c}$ mice were intraperitoneally injected with $100 \mu \mathrm{g}$ of tested samples. Control mice obtained PBS only. After 60 minutes, the mice were sacrificed and blood was collected in Eppendorf tubes. Subsequently, the serum was prepared, collected and stored at $-80^{\circ} \mathrm{C}$ for no more than 1 week.

The levels of IL-1 $\beta$, IL- 6 and TNF- $\alpha$ in serum samples were evaluated using a commercial kits OptEIA Mouse IL-1 $\beta$, IL- 6 or TNF- $\alpha$ Set, resp., (Pharmingen, San Diego, CA, USA) according to the manufacturer's instructions. The optical density was determined using a STL ELISA reader (Tecan U.S., Research Triangle Park, NC) at 450 $\mathrm{nm}$ with a correction at $570 \mathrm{~nm}$. Data shown in Figure 6 were calculated from the standard curve prepared by the automated data reduction using linear regression analysis. A standard curve was run with each assay.

\section{RNA Extraction and Reverse Transcriptase-PCR}

Total RNA was extracted from control and treated cells using Trizol reagent (Life Technologies, Inc.). RNA quality and quantity were determined by ultraviolet spec- 
trophotometry and agarose gel electrophoresis. 200ng of total RNA was reverse transcribed using SuperScript ${ }^{\mathrm{TM}}$ One-Step RT-PCR with Platinum Taq kit (Invitrogen Inc.) using gene-specific primers (Table 1) with the following conditions: $30 \mathrm{~min}$ at $50{ }^{\circ} \mathrm{C}$ followed by $2 \mathrm{~min}$ at $95^{\circ} \mathrm{C}$ and then 25 cycles of 30 s at $95^{\circ} \mathrm{C}, 45 \mathrm{~s}$ at $52^{\circ} \mathrm{C}$ for $\mathrm{NF}-\kappa \beta 2$ and $\beta$-Actin $\left(68^{\circ} \mathrm{C}\right.$ for BCL-2, $43^{\circ} \mathrm{C}$ for cdc 42$), 3$ min at $72^{\circ} \mathrm{C}$ for NF- $\mathrm{N} \beta 2$ ( $45 \mathrm{~s}$ for cdc 42 , BCL-2, 90 s for $\beta$-Actin). PCR reaction was completed by $7 \mathrm{~min}$ at $72^{\circ} \mathrm{C}$. RT-PCR products were then separated on a $1.0 \%$ agarose gel, visualized under UV light and photographed. $\beta$-Actin served as internal control.

\section{STATISTICS}

Student's t-test was used to statistically analyse the data.

\section{RESULTS}

The effects of various glucans and resveratrol on macrophages are well established. However, in order to demonstrate that a new combination of immunomodulators really exhibits an immunomodulatory characteristic, an evaluation of phagocytosis is necessary. We measured the effects of glucan and/or resveratrol complex on phagocytosis of synthetic HEMA microspheres (Fig. 1). Both glucan and resveratrol complex (RC) stimulated the internalization of synthetic particles; however, the combined preparation exhibited significant synergetic effect both on monocytes and neutrophils.

We then evaluated the effects of our substances on expression of several membrane markers. Twenty-four hrs after an ip. injection, spleen cells were isolated and the surface expression of CD4 (T helper lymphocytes), CD8 (T suppressor lymphocytes), and CD19 (B lymphocytes) was evaluated. The results summarized in Fig. 2 show that the tested substances affected only CD4 $4^{+}$lymphocytes. Again, glucan and RC showed significant synergetic effects. Conversely, the total numbers of peritoneal cells was influenced only slightly (data not shown).

We then compared the effects of a single intraperitoneal injection of the tested substances on systemic in vivo release of three cytokines, IL- 1 , IL- 6 and TNF- $\alpha$. Peripheral blood was isolated 60 min after the injection and the serum obtained was stored at $-80{ }^{\circ} \mathrm{C}$ for no longer than 1 week. The dose and time interval have been established previously ${ }^{18}$. The data summarized in Fig. 3 show significant elevation in levels of all three tested cytokines after the combined injection of glucan and $\mathrm{RC}$ complex. RC singularly stimulated release of IL-6 and IL-1, since the glucan had no effect.

Being similar to cyclophosphamide, cancerostatic drug 5-fluorouracil is well known for significant depression of immune system. We evaluated the effects of orally-given glucan or RC on fluorouracil-induced leucopenia. The data showed that whereas glucan strongly increases the recovery of bone marrow, the resveratrol complex alone showed significant stimulation but only after 10 days of application. When combined, glucan and resveratrol had small, albeit insignificant, synergetic effects (Fig. 4). A different situation was discovered in the spleen. Even if glucan again demonstrated more activity than RC, its effects showed significantly higher restoration of spleen cellularity from day 4. Combined glucan/resveratrol complex substances showed stronger synergetic effect, which was significant from day 11 (Fig. 5).

This RT-PCR Figure (Fig. 6) shows the effect of rested glucan and/or RC complex on expression level of NF-kB2, $\mathrm{Cdc} 42$ and $\mathrm{Bcl}-2$ in ZR-75-1 cells. A distinct upregulation in expression levels of NF-kB2 and Bcl-2 was evident in response to either glucan or $\mathrm{RC}$, with slightly more effect with $\mathrm{RC}$ as compared to control cells. In addition, the effect of the combined sample was similar to the effect shown by $\mathrm{RC}$ on expression of these genes. However, upregulation of $\mathrm{Cdc} 42$ expression was evident only when both immnunomodulators were used in combination.

\section{DISCUSSION}

It is important to note that despite the fact we used a concentrated RC, the levels of emodin or piceid never reached bioactive levels (data not shown).

Various types of immunomodulators, glucans in particular, well are known to stimulate phagocytosis ${ }^{19}$. Therefore, the evaluation of this basic type of immune reaction is important to determine the effectiveness of any biologically active immunomodulator. We tested the peripheral blood leukocytes for changes in phagocytosis. Using synthetic microspheres based on 2-hydroxyethyl methacrylate, we found that both tested substances caused a significant increase in phagocytosis, but the combined preparation showed significant synergetic effect both on monocytes and neutrophils. The data shown reflects the effects of a single injection of either glucan or RC. However, our preliminary experiments showed that these effects last up to 3 days after treatment (data not shown). These data were in agreement with previously published data using different types of glucan ${ }^{18}$.

Observations of the effects on expression of cell surface markers present on spleen cells demonstrated that only the numbers of CD4+ lymphocytes were influenced. Again, the combined preparation of glucan and RC showed synergetic effects. Three days after application, the increased numbers returned to normal. A similar increase in the number of CD4-positive cells after glucan application has been described for lentinan ${ }^{20}$ and Phycarine ${ }^{18}$.

In addition to the direct effect on various cells of the immune system, the immunostimulating action of $\beta$-glucans is caused by potentiation of a synthesis and release of several cytokines such as TNF $\alpha$, IFN $\gamma$, and IL-1. This cytokine-stimulating activity was found to be dependent on the triple helix conformation ${ }^{21}$. Most glucans have been shown to stimulate TNF- $\alpha$ both in vivo and in vitro ${ }^{22}$. It is hypothesized that glucans enhance leukocyte functions 


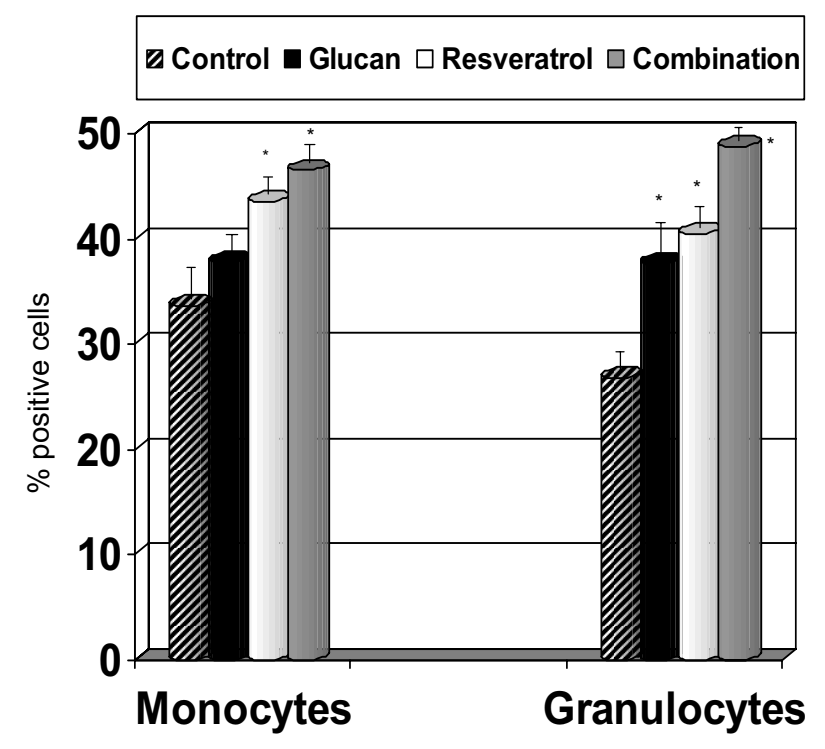

Fig. 1. Potentiation of phagocytosis of synthetic microspheres (HEMA particles) by i.p. injected glucans and/or resveratrol complex. Peripheral blood neutrophils with three and more HEMA particles were considered positive. Each value represents the mean $\pm \mathrm{SD}$. *represents significant differences at $\mathrm{P}<0.05$ level.

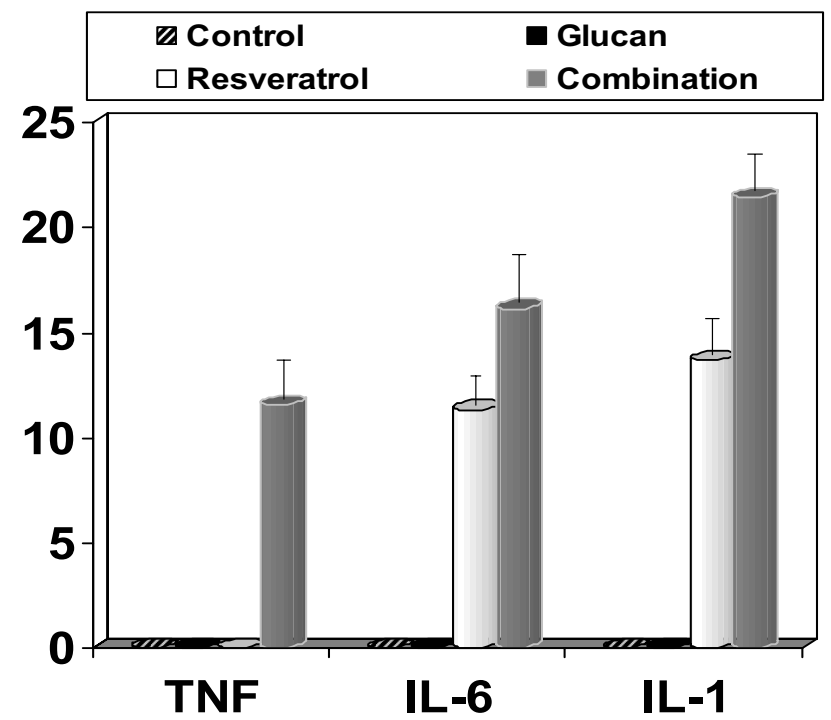

Fig. 3. Effect of different doses of injected samples on levels of TNF- $\alpha$, IL- 6 and IL- $1 \beta$ in peripheral blood. For details, see Material and Methods section. Each value represents mean \pm SD. As the control values (PBS) and glucan were always zero, each value represents significant differences at $\mathrm{P} \geq 0.05$ level.
Q Control —Glucan $\square$ Resveratrol $\square$ Combination

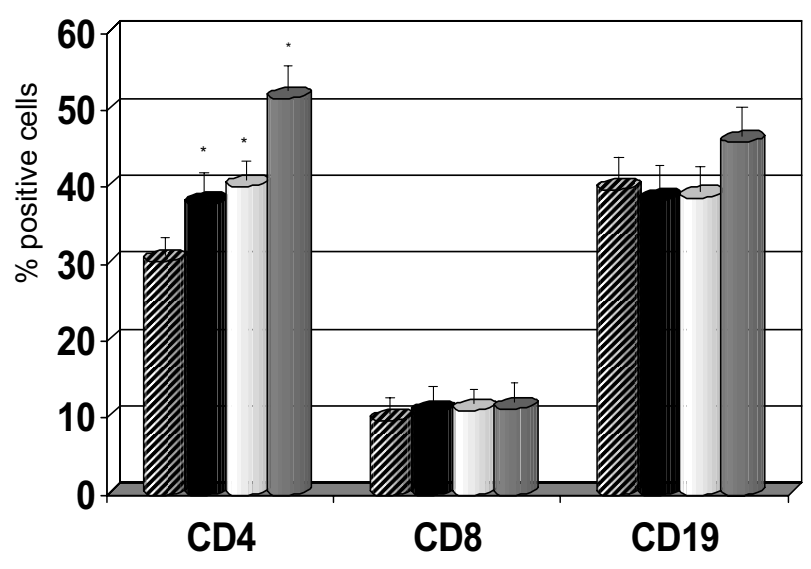

Fig. 2. Effect of ip. injection of $100 \mu \mathrm{g}$ of tested substances on the expression of CD4, CD8, and CD19 markers by spleen cells. The cells from three donors/sample were examined and the results given represent the means $\pm \mathrm{SD}$. *Represents significant differences between PBS control and tested substances at $\mathrm{P} \geq 0.05$ level.

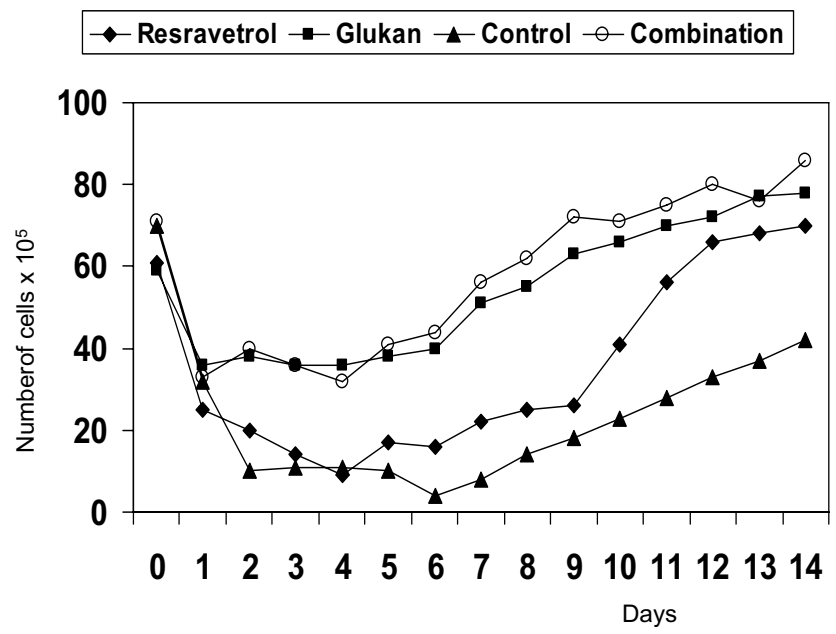

Fig. 4. Induced cell recovery in bone marrow after 5flurouracil-induced leucopenia. Starting at day 0 (injection of 5-fluorouracil), mice were orally fed, on a daily basis, with samples tested in water. Subsequently, individual mice were sacrificed and the cellularity in bone marrow was evaluated. The results represent a mean of 10 mice in 3 independent experiments. 


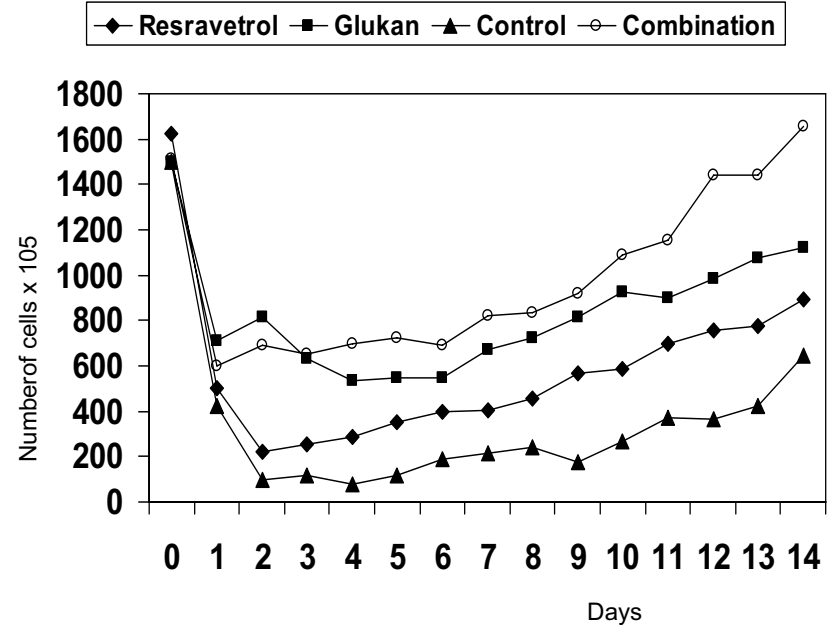

Fig. 5. Induced cell recovery in spleen after 5-flurouracilinduced leucopenia. Starting at day 0 (injection of 5-fluorouracil), mice were orally fed, on a daily basis, with samples tested in water. Subsequently, individual mice were sacrificed and the cellularity in spleen was evaluated. The results represent mean of 10 mice in 3 independent experiments.

through increased TNF- $\alpha$ secretion, particularly during early stages of infection. The elevated levels of TNF- $\alpha$ and IL-1 after Phycarine injection ${ }^{18}$ correlated with findings of effects of lentinan in the treatment of human cancer $^{23}$ and stimulation caused by Paramylon.

The potential effect of resveratrol on individual cytokines is much less clear. Some studies suggest that resveratrol can inhibit some IL-2 or TNF- $\alpha$ mediated functions ${ }^{24}$ represent only indirect proofs of the resveratrol-cytokine interaction. Therefore, the evaluation of the potential systemic effect on three model cytokines was particularly interesting. Using the previously established dose and time interval $1^{18}$, we observed the resveratrol complex-induced release of IL-1 and IL-6. In addition, the combined preparation of glucan and RC not only showed synergetic effects, but also stimulated release of TNF- $\alpha$, which was not affected by RC alone.

The major side-effects of both traditional chemotherapy and/or irradiation are leucopenia and the noteworthy suppression of the immune system, which is a significant problem in most cancer patients. These negative effects both limit the dosage and frequency of treatment ${ }^{25}$. The effects of injected glucan on enhanced recovery after experimental leucopenia have been documented ${ }^{26}$ and similar data were found after irradiation. Recent observation showed that seaweed-derived glucan can restore the leukopedia when used both intraperitoneally or oral$1 \mathrm{y}^{27}$. However, nothing is known about the resveratrol. Considering the strong synergistic effects we observed in previous experiments, it was therefore important to know if RC can similarly improve the cell recovery. Using
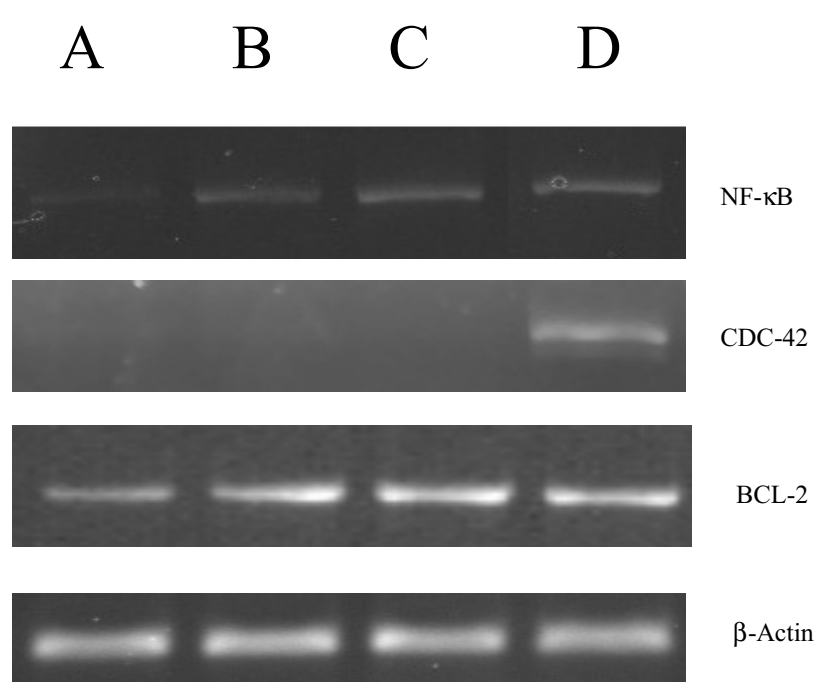

Fig. 6. Differential expression of indicated genes in response to glucan (B), resveratrol complex (C), or combined sample (D) treatment. Control sample A was treated with PBS. Equal amount of RNA from control and treated ZR-75-1 cells was subjected to RT-PCR with gene-specific primers. As a control for equivalent loading, $\beta$-actin was expressed.

a 5-fluorouracil model with well-established destruction of immune cells, we found a strong prophylactic effect of orally-given glucan. These effects are most probably caused by CR3-mediated effects of glucan on hematopoietic progenitor cells ${ }^{28}$. In bone marrow, RC alone had only limited affects and the synergistic effects were not significant. In spleen we observed different situation. Even if glucan was again significantly more active that resveratrol, its effects showed a much higher restoration of spleen cellularity from day 4. Combined glucan/resveratrol substances showed stronger synergetic effect

Upregulation of NF-kB2 gene expression is considered significant as members of this family are important regulators of cell cycle progression, cell survival, cell adhesion/angiogenesis, invasion and inflammatory responses ${ }^{29}$. They are also known to exert strong anti-apoptotic activity by inducing expression of several anti-apoptotic proteins like Bcl-2 family proteins and interfering with expression or activity of pro-apoptotic proteins ${ }^{29}$. Studies have shown the positive role of NF-kB family proteins in regulating the expression of adhesion molecules, matrix metalloproteinases and angiogenic factors which are known to increase the invasion and metastasis of cancer cells. Cdc42 belongs to the RHO-family proteins (a branch of the RAS family) and is implicated in the regulation of cell growth ${ }^{30}$. It has been reported that levels of $\mathrm{Cdc} 42$ are elevated in many different human cancers, including human breast cancer ${ }^{31}$ and that they contribute to enhanced mitogenic signaling. In addition, another recent study has suggested that $\mathrm{Cdc} 42$ can activate NF-kb by a distinct pathway ${ }^{32}$. 


\section{REFERENCES}

1. Benacerraf B, Sebestyen MM, Effect of bacterial endotoxins on the reticuloendothelial system. Fed Proc 1957; 16:860-67.

2. Rigi SJ, Di Luzio NR, Identification of a reticuloendothelial stimulating agent in zymosan. Am J Physiol 1961; 200:297-300.

3. Mimura H, Ohno N, Suzuki I, Yadomae T, Purification, antitumor activity, and structural characterization of $\beta$-1,3-glucan from Peziza vesiculosa. Chem Pharm Bull 1985; 33:5096-99.

4. Browder W, Williams D, Pretus H, Olivero G, Enrichens F, Mao $P$, et al. Beneficial effect of enhanced macrophage function in the trauma patient. Ann Surg 1990; 211:605-13.

5. Babineau TJ, Hackford A, Kenler A, Bistrian B, Forse RA, Fairchild PG, et al. A phase II multicenber, double-blind, randomized, placebo-controlled study of three dosages of an immunomodulator (PGG-glucan) in high-risk surgical patients. Arch Surg 1994;129:1204-10.

6. Stashenko P, Wang CY, Riley E, Wu Y, Ostroff G, Niederman R, Reduction of infection-stimulated periapical bone resorption by the biological response modified PGC glucan. J Dent Res 1995 74:323-30

7. Itoh W, Sugawara I, Kimura S, Tabata K, Hirata A, Kojima T, et al Immunopharmacological study of sulfated schizophyllan (SPG) I. Its action as a mitogen and anti-HIV agent. Int $\mathbf{J}$ Immunopharmacol 1990; 12:225-33.

8. Kimura Y, Tojima H, Fukase S, Takeda K, Clinical evaluation of sizofilan as assistant immunotherapy in treatment of head and neck cancer. Acta Otolaryngol 1994; 511 (Suppl.):192-95.

9. Braaten JT, Wood PJ, Scott FW, Wolynetz MS, Lowe MK, BradleyWhite $\mathrm{P}$, et al. $\beta$-glucan reduces blood cholesterol concentration in hypercholesterolemic subjects. Eur J Clin Nutrition 1994;48:46574.

10. Czop JK, Austen KF, Properties of glycans that activate the human alternate complement pathway and interact with human monocytes beta glucan receptors. J Immunol 1985; 135:3388-93.

11. Thornton BP, Vetvicka V, Pitman M, Goldman RC, Ross GD, $\beta$ glucan-binding lectin site of complement receptor type 3 (CD11b/ CD18). J Immunol 1996; 156:1235-46.

12. Taylor PR, Brown GD, Reid DM, Willment JA, Martinez-Pomares $\mathrm{L}$, Wong SY, et al. The beta-glucan receptor, dectin-1, is predominantly expressed on the surface of cells of the monocyte/macrophage and neutrophil lineages. J Immunol 2002; 169:3876-82.

13. Gao X, Xu XY, Janakiraman N, Chapman RA, Gautam SC, Immunomodulatory activity of resceratrol: suppression of lymphocyte proliferation, development of cell-mediated cytotoxicity, and cytokine production. Biochem Pharmacol 2001; 62:12991308.

14. Losa GA, Resceratrol modulates apoptosis and oxidation in human blood mononuclear cells. Eur J Clin Invest 2003; 33:818-23.

15. Bertelli AAE, Ferrara F, Diana G, Fulgenzi A, Corsi M, Ponti W, et al. Resveratrol, a natural stilbene in grapes and wine, enhances intraphagocytosis in human promononocytes: a co-factor in antiinflammatory and anticancer chemopreventive activity. Int J Tissue React 1999; 21:93-104.
16. Aziz A, Poinssot B, Daire X, Adrian M, Bezier A, Lambert B, et al. Laminarin elicits defense responses in grapevine and induces protection against Botrytis cinerea and Plasmopara viticola. Mol Plant Microbe Interact 2003;16:1118-28.

17. Vetvicka V, Holub M, Phagocytic activity of peritoneal and omental macrophages of athymic nude mice. Immunol Invest 1988; 17:53141.

18. Vetvicka V,Yvin J-C, Effects of marine beta-1,3 glucan on immune reactions. Int Immunopharmacol 2004; 4:721-30.

19. Abel G, Szollosi J, Chihara G, Fachet J, Effect of lentinan and mannan on phagocytosis of fluorescent latex microbeads by mouse peritoneal macrophages: a flow cytometric study. Int $\mathbf{J}$ Immunopharmacol 1989;11:615-21.

20. Arinaga S, Karimine N, Takamuku K, Nanbara S, Nagamatsu M, Ueo $\mathrm{H}$, et al. Enhanced production of interleukin 1 and tumor necrosis factor by peripheral monocytes after lentinan administration in patients with gastric carcinoma. Int J Immunopharm 2002; 14:43-7.

21. Falch BH, Espevik T, Ryan L, Stokke BT, The cytokine stimulating activity of (1-3)- $\beta$-D-glucans is dependent on the triple helix conformation. Carbohydrate Res 2000; 329:587-96.

22. Ross GD, Vetvicka V, Yan J, Xia Y, Vetvickova J, Therapeutic intervention with complement and $\beta$-glucan in cancer. Immunopharmacol 1999;42:61-74.

23. Abe Y, Miyake M, Miyazaki T, Horiuchi A, Kimura S, The endogenous induction of tumor necrosis factor serum (TNS) for the adjuvant postoperative immunotherapy of cancer - changes in immunological markers of the blood. Jap J Surg 2002; 20:19-26.

24. Kolgazi M, Sener G, Cetinel S, Gedik N, Alican I, Resveratrol reduces renal and lung injury caused by sepsis in rats. J Surg Res 2006; 134:215-21.

25. van der Vijgh WJ, Peters GJ, Protection of normal tissue from the cytotoxic effects of chemotherapy and radiation by amifostine (Ethyol): preclinical aspects. Semin Oncol 1994; 21:2-7.

26. Turnbull JL, Patchen ML, Scadden DT, The polysaccharide, PGGglucan, enhances human myelopoiesis by direct action independent of and additive to early-acting cytokines. Acta Haematol 1999; 102:66-71.

27. Vetvicka V, Dvorak B, Vetvickova J, Richter J, Krizan J, Sima P, et al. Orally-administered marine $\beta-1,3$ glucan Phycarine stimulates both humoral and cellular immunity. Int J Biol Macromol 2007; 40:291-8.

28. Cramer DE, Allendorf DJ, Baran JT, Hansen R, Marroquin J, Li B, et al. Beta-glucan enhances complement-mediated hematopoietic recovery after bone marrow injury. Blood 2006;107:835-40.

29. Ravi R, Bedi A, NF-kappaB in cancer-a friend turned foe. Drug Resist Updat 2004; 7:53-67.

30. Lin R, Bagrodia S, Cerione R, Manor D, A novel Cdc42Hs mutant induces cellular transformation. Curr Biol 1997; 7:794-7.

31. Pan Y, Bi F, Liu N, Xue Y,Yao X, Zheng Y, et al. Expression of seven main Rho family members in gastric carcinoma. Biochem Biophys Res Commun 2004; 315:686-91.

32. Murphy GA, Jillian SA, Michaelson D, Philips MR, D'Eustachio P, Rush MG, Signaling mediated by the closely related mammalian Rho family GTPases TC10 and Cdc42 suggests distinct functional pathways. Cell Growth Differ 2001; 12:157-67. 